\title{
Airport Capability, Aviation Activity and Economic Activity at General Aviation Airports
}

\author{
Stephen M. Swartz \\ Auburn University \\ Pamela S. Donovan \\ University of North Texas \\ Terry L. Clower \\ George Mason University
}

\begin{abstract}
Previous research has established support for the overall premise that there are relationships between investments in airport infrastructure and economic activity. The nature of the investment and resulting increased capabilities seem to act in specific ways that are as yet materially unexplained. In addition, the role of how increased capabilities support (or make possible) increased activity at the airport, and how increased activity in general leads to economic outcomes are also ripe for additional clarification. The purpose of this investigation is to shed light on the relationships between airport capabilities, aviation activity at the airport, and the economic activity generated for the community served by the airport. In this study we have demonstrated that strong, significant positive relationships exist between Airport Capabilities (Accessibility and Infrastructure), Airport Size (Class), Airport Activity, and Economic Activity. Practical, managerial inferences can also be drawn. First, it is not unreasonable to expect that investment (public or private) in improved airport capability does indeed stimulate increased economic activity directly, and indirectly by increasing the number and importance of activities taking place at the airport. It is anticipated that the results of this and related future research efforts can better inform public policy decisions in general aviation.
\end{abstract}

\section{Introduction}

Public entities at Local, State, and Federal levels collect revenues from taxpayers and invest those revenues to provide a variety of services and capabilities to serve their constituencies and ensure public welfare. The development of federally and state funded transportation infrastructure is one such public investment designed to promote multiple objectives. For example, the primary purpose of the U.S. Department of Transportation (USDOT) is to ensure a "a fast, safe, efficient, accessible and convenient transportation system" that enhances quality of life, supports current and future national interests, and enables the nation's economic growth (USDOT, 2012). The most recent piece of U.S. legislation, Moving Ahead for Progress in the $21^{\text {st }}$ Century Act (MAP-21), allocated \$105 billion for fiscal years 2013-2014 to ensure the "growth and development of the country's vital transportation infrastructure" (USDOT, 2014). Allocating public funding to projects that will 
achieve these goals falls to a variety of decision-makers depending on the scope and scale of the project. For example, the Federal Aviation Administration (FAA), State Departments of Transportation, and Local County and City councils manage and develop the aviation infrastructure across the U.S. and prioritize publicly funded airport projects.

The FAA manages air transportation infrastructure as part of the National Plan of Integrated Airport Systems (NPIAS) and uses the Airport Improvement Plan (AIP) program as the primary funding vehicle (FAA, 2012b; 2014b). These investments are intended to increase the capabilities of the airports and facilitate aviation activities in the National Airspace System (NAS). For example, AIP grants have been used to widen and lengthen runways to allow for a wider variety of aircraft operations; and to upgrade navigational aids to increase the range of weather conditions under which safe operations can be conducted. One anticipated outcome from an increase in airport activities is an increase in economic activity in the community served by the airport (FAA, 2012a).

While aviation's role in economic development is widely accepted, Freestone and Baker (2011) acknowledge that airports as economic drivers are under-researched. The airport planning literature, historically, has focused on safety, land-use compatibility, and environmental impacts in an effort to balance the economic and social benefits of the airport with the costs and negative perceptions associated with the accompanying congestion and noise. Airports were first recognized as economic zones in the 1960's and 70's, with the introduction of jet aircraft, contributing to the development of industrial parks at major metropolitan airports (Kasner, 1997). However, it wasn't until the late 1990's that research considered airports as economic drivers when the contribution of aviation to globalization was realized in the post-deregulation era with the growth and expansion of airline networks and the development of multi-modal hubs at or near metropolitan airports (Freestone \& Baker, 2011). One stream of research focuses on defining the typology of airport-centric development, such as on- or near-airport development (Blanton, 2004), airport cities (Peneda, Reis \& Macario, 2011), and "Aerotropolis" metropolitan development (Kasarda, 2000) versus the "Airea" sub-regional development approaches (Schlaack, 2010). This existing body of research is primarily directed at large commercial airports and urban development, identifying the factors that contribute to or constrain urban growth.

However, fewer studies have examined the mechanisms of airport-centric economic growth (Freestone \& Baker, 2011), particularly in context of general aviation (GA) airports. This raises the question about whether the same factors that facilitate airport-centric economic growth in a metropolitan setting translate to the GA airport. Furthermore, the approval authority for airport investment at GA airports often resides with the City or County Councils, where airport investment decisions are not well understood (Weisbrod, 1990) and compete with other community investment interests. Therefore, a better understanding of the types of airport investment at GA airports that contribute the greatest to economic growth is needed to help decision makers in allocation of public funds. For example, a decision surrounding the allocation of tax monies for investment in airport infrastructure, capacity, navigational aids, or in generating business vs. leisure related aviation activities would be a concern for the leadership of airport governance organizations. 
The purpose of this investigation addresses this last question, by examining the nature of the relationships between airport capabilities (in support of aviation activities) and economic activity at general aviation airports. Three research questions guided this study:

1. What is the nature of the relationships between Airport Capabilities and Aviation Activities at GA airports?

2. What is the nature of the relationships between Aviation Activities and Economic Activity at GA airports?

3. What aspects of Airport Capability and Airport Activity are most closely related to Economic Activity at GA airports?

This paper makes three important contributions to the body of knowledge. First, we provide empirical evidence for the relationships between Airport Capabilities, Aviation Activity, and Economic Activity. Second, we provide insight on the relative contributions of Airport Capabilities and Aviation Activity to the Economic Activity at GA airports. Airport owners and managers can use these insights to establish investment and operational priorities at their airports. And finally, we provide a foundation to guide future research.

\section{The Nature of Economic Activity at the Airport}

The economic role of an airport is complex, varied and difficult to classify-even at small general aviation facilities (Kanafani \& Abbas, 1987). The direct economic impact can be measured in terms of economic activity (expenditures, sales revenue, and wages) at the airport. Additionally, there is an indirect economic impact that extends beyond the airport. These indirect effects include the activities of business travelers in the local economy (hotel, restaurant, and retail spending), business expansion and development (associated jobs and business income) due to access to transportation at the airport, and user benefits (time and cost savings).

The Federal Aviation Administration (FAA) regularly conducts analyses of costs and benefits of the 3,330 airports included in the NPIAS eligible for public funding (FAA, 2012a). Of the 3,330 airports in the NPIAS, only 378 are large airports offering regularly scheduled air service and familiar to the travelling public, while the remainder includes smaller commercial service airports and general aviation facilities (FAA, 2012b). In 2012, the FAA conducted an assessment of GA airports in the United States in order to assist decision makers in allocating public investment into more effective projects to improve airport capabilities (FAA, 2012a). One outcome of the assessment was a new classification system for GA airports based on the scope and number of aviation activities at the airport, specifically identifying airports as National, Regional, Local or Basic general aviation airports. The FAA identified 30 discrete activities in 5 major categories, as shown in Table 1. This new classification system replaced the older classification system (limited commercial service or reliever) and more accurately captures the diverse manner in which GA airports have evolved to support their local communities and the NAS. The FAA will use the new GA classification system to assist in the allocation of investment funds through the AIP among the GA airports in an effort to improve the "public payback" as part of the NPIAS (FAA, 2012a). 
Table 1.

General Aviation (GA) Airport Activity Classification

\begin{tabular}{ll}
\hline Category & Examples of Aviation Activities \\
\hline \multirow{2}{*}{ Emergency Preparedness and } & Aeromedical \\
& Law Enforcement \\
& Homeland Security \\
& Aerial Fire Fighting \\
& Search and Rescue \\
\hline \multirow{2}{*}{ Critical Community Access } & Air Taxi \\
& Air Charter \\
& Essential Scheduled Air Service \\
\hline \multirow{3}{*}{ Other Aviation Specific Functions } & Self Piloted Business \\
& Corporate Aviation \\
& Flight Instruction \\
& Personal Flying \\
& Aircraft Storage \\
& Aerospace Research \\
\hline \multirow{2}{*}{ Commercial, Industrial, and } & Agricultural Application \\
Economic Activities & Aerial Surveying \\
& Oil and Mineral Survey \\
& Express Delivery \\
\hline \multirow{2}{*}{ Destination and Special Events } & Air Cargo \\
\hline
\end{tabular}

In addition to the contribution of GA airports to the general public welfare, studies have also focused on quantifying the magnitude of the contribution of related aviation activities at GA airports to economic activity (ACI-NA, 2012; FAA, 2011). For one example, "Business Aviation" (separate from air transportation services holding out commercial carriage to the general public) became an area of interest relatively recently. Business aviation is an increasing activity at GA airports. In 2012, 9,600 business aircraft operated in North America and is expected to grow by 2\% annually; up to 13,640 by 2032 (Bombardier, 2013). The FAA estimated that the national economic impact of civil aviation totaled $\$ 1.3$ trillion and accounted for $5.2 \%$ of U.S. gross domestic product (GDP) in 2009. Of the $\$ 1.3$ trillion in total aviation output, general aviation was credited with contributing $\$ 14.4$ billion (FAA, 2011).

This study followed standard practice in estimating economic impact by measuring economic activity based on the value of aviation-related expenditures by private industry (payrolls, taxes paid, operating expenses) and public agencies (federal, state and local spending on infrastructure, payrolls, services contracts, supplies). The effects were disaggregated into 7 primary categories: airline operations, airport operations, general aviation, aircraft manufacturing, air couriers, visitor expenditures, and travel arrangements. The impact analysis also included an estimate of economic activity as a result of the "enabling effects" of air transportation; e.g., activity that would not otherwise have occurred but for some air transportation capability represented by aviation related activities (FAA, 2011).

Typically, economic impact studies assess "direct," "indirect," and "induced" or "multiplier" activity as separable components of overall activity. Direct activity is the flow of dollars as a result of the aviation activity specifically (e.g., operational spending by the airport or airport tenants). The indirect economic activity includes 
the flow of dollars that result from activities that are a consequence of secondary and tertiary aviation-related business activities - these are the second- or higher-order effects that would not have occurred without the aviation activity (e.g., purchase of parts by aircraft maintenance shops and payrolls of on-site restaurants and shops at the airport). Induced effects represent economic activity associated with household spending from the salaries and wages earned through direct and indirect business activities and spending. The FAA study used data from existing government databases and filings from the Census Bureau, Bureau of Transportation Statistics, Bureau of Labor Statistics, and State and Federal budget data among other sources. Using a slightly different approach, the aviation group at consulting, engineering, and research firm CDM Smith performed a comprehensive, nationwide survey of state economic impact studies in 2012 (ACI-NA, 2012). While the methods vary slightly among states, most economic impact studies follow the FAA procedure relatively closely, defining "economic activity" as the sum total of aviation related spending by public and private entities. The ACI-NA study estimated direct economic activity to be over $\$ 460$ billion, with secondary or "multiplier effects" up to $\$ 718$ billion for a total economic activity related to aviation activity around $\$ 1.2$ trillion. These studies included "commercial aviation" which is comprised of both scheduled and unscheduled aviation activity across a broad variety of specific aviation activities like air transportation, agricultural application, flight training, aerial surveying, medical evacuation, etc. This study is particularly interested in the role of aviation activity defined under the subcategory "general aviation" or non-airline type operations conducted at the vast majority of smaller airports without any scheduled air services.

While the generation of economic activity as a result of infrastructure investment continues to be an area of interest for investigation, few studies have attempted to explicitly include specific activities being performed as a significant variable of interest. Researchers have used a variety of "input" measures (operating costs or investment) and "output" measures (service provided, taxable revenue generated) as the main factors of interest. Airport characteristics (similar to "capabilities" as used in this research) are frequently classified as a type of output; e.g. runway length or number and type of operations as the result of investment input. Another common practice is to use airport characteristics/capabilities as moderating or mediating variables between inputs and outputs. The use of efficiency or productivity assessments (some ratio of inputs to outputs) is a very common approach. Many international studies provide examples of this approach (Francis, Humphreys \& Fry, 2002; Humphreys \& Francis, 2002; ICAO, 2002; Oum, Yu \& Fu, 2002). Airport characteristics are included as moderators or mediators; capacity measures like runway length, nature of navigational aids available, ramp space, type of services offered, etc. are commonly used. Of course, productivity or efficiency measures are commonly used in lieu of "profit" type measures due to the involvement of public monies used in the development and management of many airports.

An early example of research intended to describe relationships between economic activity at airports and economic development investment was conducted by Cambridge Systematics (Weisbrod, Reed, \& Neuwirth, 1993). Their analysis of a sample of 30 airports in Europe, Japan, and North America was part of an effort to develop a predictive model for economic development associated with large commercial and smaller general aviation airports. The model inputs considered as predictor variables were: Economic Characteristics of the Airport Area (population, GDP, employment, etc.), Air Service Functional Characteristics (number of flights, cities served, regional/national/international connections, etc.), Other Airport Functions (maintenance, charter, military, etc. activities), Airport Land Characteristics (landside connections, nearby business space, distance to prestige locations, etc.), and Metropolitan Market Orientation (main business activities of closest city). They developed a classification system for economic development activity or output associated with the airport that 
included: employment by location, gross and net regional and local income, and gross and net building floor space utilized.

A more recent representative example of the "productivity" approach was published in 2002 and summarized in 2003. The Air Transport Research Society (ATRS) published the results of their Global Airport Benchmarking Task Force. The study attempted to measure the productivity performance of 50 major airports in Asia, Europe, and North America. The team explicitly recognized that "The airport industry is very diverse and heterogeneous with a high degree of quality differentiation, different ownership and regulatory structures, different mixes of services and operating characteristics, as well as external constraints such as location and environmental factors" (Oum et al., 2002).

Previous studies of airport economic performance have differentiated airport activities using two categories of activity; primarily "landside" vs. "airside" (Gillen \& Lall, 1997; Pels, Nijkamp, \& Rietveld, 2001). Differentiating on this basis was rejected by the ATRS study and Oum. This decision was based on the recognition that activity on the landside was directly driven by and integrated with activity on the airside. Also, previous work had not uncovered significant enough differences to merit this analytical contrast. Other studies have used a three dimensional taxonomy of airport economic activity proposed by Doganis (Doganis, 1992; Doganis, Lobbenberg, \& Graham, 1995). This model includes Essential Operational Services, Traffic-Handling Services, and Commercial Activities. Theory supports the use of this contrast based on two related assumptions. First, Operational Services and Traffic Handling Services, while both inherently "governmental" functions, have very different organizational goals and hence performance expectations and measures. This would separate them each from the other; and certainly separate them from the very different "for profit" motivations of Commercial Services. The second assumption is that organizations with different objectives and performance expectations need to be assessed differently by different metrics. This approach was also rejected by Oum in analyzing the ATRA data set.

As with some previous studies, Oum et. al. (2002) do not specifically focus on categorizing activities on airports. They defined airport characteristics using 2 aggregate measures of "capacity" (annual enplanements and average flight capacity), one measure of "connectedness" (\% of flights operating internationally), and one "economic" measure (percent of revenues generated from transportation vs. support activities). The economic measure was the only attempt to classify airports by the type of activities performed by organizations on the airport. The output measure focused on productivity/efficiency and the authors developed many complex measures of productivity in their analysis.

In a case study, Peneda et. al. (2011) identified four critical factors that facilitate the development of airport cities: connectivity of transportation infrastructure and markets, economic potential of the area, commercial attitude of the airport operator, and sustainable development via collaborative and integrated planning. Robertson (1995) examined the ability of airports to drive job growth and economic regeneration in the United Kingdom. Of course, economic growth often comes at a cost; long standing concerns about noise, pollution, congestion, property value, and accident risk are legitimate citizen concerns about airport operations, and various governance organizations are receptive to those arguments in limiting growth (Freestone \& Baker, 2011). Indirectly, if economic growth is designed to attract labor, commercial and industrial companies, entrepreneurs, investment, political interest, and intellectual capital (Sheffi, 2012), then the associated costs associated with those activities are also considered as airport costs. 
Previous research has established support for the overall premise that there are relationships between investments in airport infrastructure and economic activity. However, these studies are also very careful to recognize that understanding the nature of this relationship is confounded by the influences of the various externalities involved. The nature of the investment and resulting increased capabilities seem to act in specific ways that are as yet materially unexamined. In addition, the role of how increased capabilities support (or make possible) increased activity at the airport, and how increased activity in general leads to economic outcomes are also ripe for additional clarification. It is the purpose of this investigation to shed light on the relationships between airport capabilities, aviation activity at the airport, and the economic activity generated for the community served by the airport.

\section{Methodology}

To study the relationships between Airport Capabilities (AC), Aviation Activities (AA), and Economic Activity (EA) at general aviation airports, we propose the baseline theoretical model in Figure 1. "Airport Capability" refers to ease of use and variety of operations supported, based on the characteristics of the airport and associated navaids and infrastructure. "Airport Activity" refers to the nature, number, and type of operations (both ground and air based) conducted in and around the airport, that rely on the airport in some material way (would not otherwise happen but for the presence of the airport). "Economic Activity" refers to the flow of dollars and products associated with the operations being conducted at the airport, assessed using standard practices recognized by economists and the FAA in analyzing aviation-related commerce. Each construct will be described in greater detail (variables used and how they were measured and analyzed) in the following paragraphs.

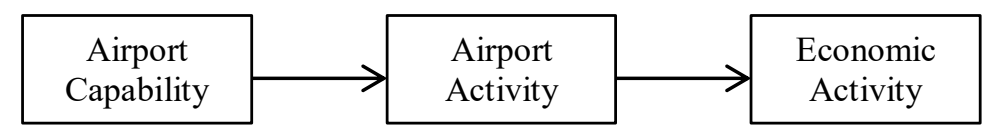

Figure 1. Baseline Theoretical Model

With the broad theoretical model as a foundation, we propose that higher levels of AC and AA lead to an increase in EA. Furthermore, we suggest that AA at the airport mediates the relationship between AC and EA.

\section{Data Collection}

The data used in this study was collected using surveys, interviews, and secondary data sources as part of project funded by the Texas Department of Aviation (TXDOT) to assess the economic significance of general aviation airports in Texas (TXDOT, 2011). There are 1,461 airports in Texas, the state airport system plan includes 292 of them for public investment and development. Of these, 25 provide scheduled air service ("non GA") and 42 are very small rural airports that were not surveyed. Therefore, 225 GA airports included in the state system plan were surveyed, and 146 responded for an overall $65 \%$ response rate.

The survey instruments used in this research (airport managers surveys, airport business tenant surveys, and itinerant pilot surveys) followed the format and content of previous research projects undertaken by the Texas Department of Transportation (TXDOT, 2005). This allowed comparisons to be made with the previous 
research to identify possible errors and omissions in completing the survey instruments. In the case of airport manager surveys, this also meant that many of the respondents had completed the same survey for an earlier time period. Surveys from business tenants were compared to data available from a national business database published by InfoGroup. The InfoUSA database was also used to provide employment estimates from nonrespondent tenants. Due to incomplete responses on some key variables used in this study, 112 usable instruments were analyzed.

\section{Total Annual Economic Activity}

The economic activity data was collected through a combination of interviews, surveys and secondary data sources. Interviews and surveys were conducted with airport managers and managers of airport tenant operations. Investment and spending (capital improvement), revenue, cost, aviation activity and airport capability data were collected for 2010. Secondary data sources were used (government and regulatory agency filings) to collect and verify employment and sales economic data as well as the numbers and levels of various aviation activities conducted at the airport. Over 300 transient and itinerant pilots operating at general aviation airports in Texas also provided data on spending in support of aviation related activities. The data gathered from transient and itinerant pilots was compared with the results of other similar surveys performed by Wilbur Smith \& Associates to verify the reasonableness of spending estimates.

Spending, revenue, or employment data served as input for the IMPLAN economic input-output model from MIG, Inc (2014). For each spending category, appropriate industry sectors were selected using the IMPLAN sectoring scheme. We treat the spending data as output to final demand. Where appropriate, retail trade margins were applied before entering the spending data. For most of the participating business tenants, the response of choice was employment levels at the relevant facility. The IMPLAN model has the option of using employment as a data input and then estimates output to final demand based on national product account prepared by the Bureau of Economic Analysis. The IMPLAN model produces estimates of total direct, indirect and induced effects for output, employment, and labor income for the defined study area. In this analysis, the defined study area for each airport is the airport's host county. If an airport's property falls within the jurisdictional boundaries of more than one county, the study area is the combined counties.

The total economic activity (EA) at each airport measures the total amount of dollars flowing as a result of airport and related business operations in calendar year 2010 (see Table 2). The EA variable is the sum of the direct, indirect, and induced impacts of airport operations spending, business operations at business tenants, and the spending of transient and itinerant pilots for lodging, fuel, dining, entertainment and other spending.

The total EA variable was transformed using the Box-Cox transformation to correct a positive skew in the dataset (Box \& Cox, 1964). Normality was confirmed using histograms, probability plots, and a scatter plot against the independent variables.

\section{Airport Activity}

The airport activity (AA) data were collected from survey data reported by each airport manager and secondary sources (air traffic control count data). Airport activity measures the total number of aircraft operations at the airport in 2010, as shown in Table 2. Airport activity included a full range of operations such as business support, flight training, commercial and military operations, etc. following the characterizations from the 2012 FAA study FAA (2012a). 
Table 2.

General Aviation Airport Sample (N =112)

\begin{tabular}{lrrrr}
\hline & Mean & SD & Min & Max \\
\hline Economic Activity & $\$ 50,514,014$ & $\$ 257,566,496$ & $\$ 169,975$ & $\$ 2,022,220,389$ \\
Annual Airport Activity & 15,003 & 33,475 & 36 & 208,248 \\
\hline
\end{tabular}

The survey instrument included 21 types of activities and items for respondent provided activity descriptions as described earlier in the paper (see Table 1. General Aviation Airport Activity Classification). Airport executives were asked to provide numerical counts per month and an estimate of the overall importance of the activity to the community. A lognormal data transformation was used to correct a positive skew in the dataset and normality was confirmed.

\section{Airport Capability: Accessibility and Infrastructure}

Airport Capability (AC) refers to the degree to which the airport is accessible under a wide range of environmental conditions by a range of aircraft. We considered $\mathrm{AC}$ a multidimensional construct, with the range of weather conditions that impact aircraft operations separable from the range of aircraft (e.g., size, speed, type) that can use the airport. "Accessibility" (ACCESS) refers to the range of weather conditions under which safe operations can be conducted. "Infrastructure" refers to the inherent ability of the airport to handle larger and faster (more capable) aircraft. We hypothesize that some airport capabilities particularly well suited to stimulate airport activity at and through the airport as a way to stimulate economic development and the quality of life/standard of living for a served population.

Airport Accessibility. We examined several variables that comprise the decision set for safe landings at an airport under a range of weather conditions. One of the primary considerations is the suitability of the terminal navigational guidance under reduced visibility and the height of clouds during inclement weather (FAA, 2014a). The FAA certifies "Approaches" to a safe landing based on how low to the ground the cloud bases can be, and what visibility distance exists under the clouds. Less accessible airports have higher cloud base minimums and longer visibility requirements for a safe landing; in other words, better weather. More accessible airports have navigational aids that allow pilots to land safely (flight crew training and aircraft capability permitting) during very low clouds and greatly reduced visibility.

Four variables were selected to measure the airport accessibility construct. First, the number of "precision" vs. "non-precision" landing approaches was used. Precision and non-precision approaches are defined by the FAA as meeting higher standards for accuracy and reliability (precision) or lower standards (non-precision). Next, we measured the "decision height" (in feet) above the approach end of the runway. This corresponds to the minimum height above the ground the pilot may descend in the clouds before having to cancel his or her landing and fly to an airport with better weather. We also measured the instrument landing system (ILS) runway visual range required for a safe landing (in miles). Better, more accurate ILS equipment allow pilots to continue their landing under lower visibility distances. Lower minimums and lower visibility numbers correspond to higher levels of accessibility during inclement weather. 
Data for these variables were collected from the FAA published landing minimums for each airport in the dataset. The number of runway approaches was standardized by dividing each variable (the number of precision and non-precision approaches) by the number of runways at the airport. We standardized the number of approaches because the objective was to measure the airport capability rather than airport size. For example, if we compare two airports, each with a single runway, we assumed that the airport with two precision approaches on the runway is accessible under a wider variety of aircraft and weather conditions than the airport with only one precision approach on the runway. Additionally, we included the number of runways in the airport infrastructure construct and wanted to avoid collinearity or construct overlap in the model. The data for decision height above the approach end of the runway and ILS visibility range were reverse scored, so that larger values correspond to higher levels of accessibility by aircraft under adverse weather conditions.

Principal component analysis (PCA) was used to reduce the airport accessibility variables into a single measure for each airport (see Table 3). PCA is appropriate when there is redundancy among the observed variables and the objective is to reduce the number of variables, while accounting for the majority of the variance in a set of observed variables. The components were extracted, keeping those with an Eigen value $>1$. One component was extracted $(\lambda=2.64)$ that accounted for 66 percent of the total variance in the variables. A factor loading greater than 0.5 can be considered meaningful (Pedhazur \& Schmelkin, 1991), in PCA. The only factor loading that did not meet this criterion was the number of precision approaches per runway, as shown in Table 3. This was most likely due to the large number of general aviation airports in our sample that do not have precision approach runways. However, as a measure of airport accessibility, we believe it was important to include this variable, particularly since it is very close to the recommended factor loading. The extracted component was negatively skewed. To correct this, a Box-Cox transformation was applied (Box \& Cox, 1964). Normality was confirmed using histograms, probability plots, and a scatter plot against the dependent variable, Economic Activity.

Table 3.

Airport Accessibility: Factor Loadings, Descriptive Statistics, and Correlations

\begin{tabular}{|c|c|c|c|c|c|c|c|}
\hline & $\begin{array}{l}\text { Factor } \\
\text { Loadings }\end{array}$ & Mean & SD & 1 & 2 & 3 & 4 \\
\hline 1 Num_PrecAprch/Runway & 0.446 & 0.112 & 0.291 & 1.000 & & & \\
\hline $\begin{array}{l}2 \text { Num_NonPrecAprch/Runw } \\
\text { ay }\end{array}$ & 0.793 & 1.705 & 1.102 & 0.145 & 1.000 & & \\
\hline 3 Rev_BestDecisionHeight & 0.947 & 965.393 & 432.044 & $0.294^{* *}$ & $0.657^{* * *}$ & 1.000 & \\
\hline 4 Rev_BestVisualRange & 0.957 & 1.755 & 0.784 & $0.357^{* * *}$ & $0.650^{* * *}$ & $0.949^{* * *}$ & 1.000 \\
\hline
\end{tabular}

Airport Infrastructure. The second measure of airport capabilities included the airfield infrastructure at the airport. Airport infrastructure (INFRA) measured the capability of the airfield in terms of the number of runways, the length of the longest runway (in feet), the maximum weight bearing capacity of the runway system (in thousands of pounds), and whether there was an air traffic control tower on the airfield $(0=$ no, $1=$ yes). The airfield infrastructure data were collected from the FAA Airport Master Record Data (Form 5010) for the airports in this study. Principal component analysis was used to construct a single variable to measure the airport infrastructure. The components were extracted, keeping those with an Eigen value $>1$. One component was extracted $(\lambda=2.345)$ that accounted for 58.6 percent of the total variance in the variables. The factor 
loadings (see Table 4) suggest that each variable satisfactorily measures airport infrastructure. The extracted component was positively skewed. To correct this, a Box-Cox transformation was applied to the infrastructure component (Box \& Cox, 1964). Normality was confirmed using histograms, probability plots, and a scatter plot against the dependent variable, Economic Activity.

Table 4.

Airport Infrastructure: Factor Loadings, Descriptive Statistics, and Correlations

\begin{tabular}{|c|c|c|c|c|c|c|c|}
\hline & $\begin{array}{c}\text { Factor } \\
\text { Loadings }\end{array}$ & Mean & SD & 1 & 2 & 3 & 4 \\
\hline 1 Number Runways & 0.599 & 1.55 & 0.68 & 1.000 & & & \\
\hline $\begin{array}{l}2 \text { Longest Runway (in } \\
\text { feet) }\end{array}$ & 0.854 & 5129.49 & 1306.70 & $0.400^{* * *}$ & 1.000 & & \\
\hline $\begin{array}{l}3 \text { Max Wt Bearing } \\
\text { Capacity }\end{array}$ & 0.838 & 53.26 & 100.50 & $0.309^{* * *}$ & $0.655^{* * *}$ & 1.000 & \\
\hline 4 ATCT & 0.745 & 0.14 & 0.35 & $0.268^{* *}$ & $0.481^{* * *}$ & $0.511^{* * *}$ & 1.000 \\
\hline
\end{tabular}

\section{Airport Size}

Airport Class (SIZE) was used as a proxy for airport size and measures the scale of operations at the airport in terms of airport employees. The airports in the sample were categorized based on the number of airport employees (FTE, full-time equivalents) as shown in Table 5. We assume that as the scale and scope of airport operations increase so does the number of employees required to manage these operations. Class 1 through 3 was assigned to the dataset based on self-reported employment data for calendar year 2010. Class 4 was assigned to airports designated as commercial service airports or general aviation reliever airports in the FAA National Plan of Integrated Airport Systems (NPIAS). This variable was used as a control variable.

Table 5.

Airport Class Definitions $(\mathrm{N}=112)$

\begin{tabular}{ccc}
\hline Airport Class & Airport Employees & $\begin{array}{c}\text { Number } \\
\text { in } \\
\text { Sample }\end{array}$ \\
\hline 1 & $<0.6$ FTE & 15 \\
2 & $0.6-4.0$ FTE & 17 \\
3 & $>4.0$ FTE & 63 \\
4 & Comm Service or GA & 17 \\
\hline
\end{tabular}

\section{Constructs, Hypotheses and Theoretical Model}

The individual constructs have been described and tested for internal reliability and validity in the previous sections. Before proceeding to the analysis, it would be instructive to restate and clarify the overall relationships between the constructs and associated hypotheses in light of the theoretical model. The revised model (shown 
in Figure 2) describes and includes the results of clarifying and disaggregating the constructs of interest and the relationships between them.

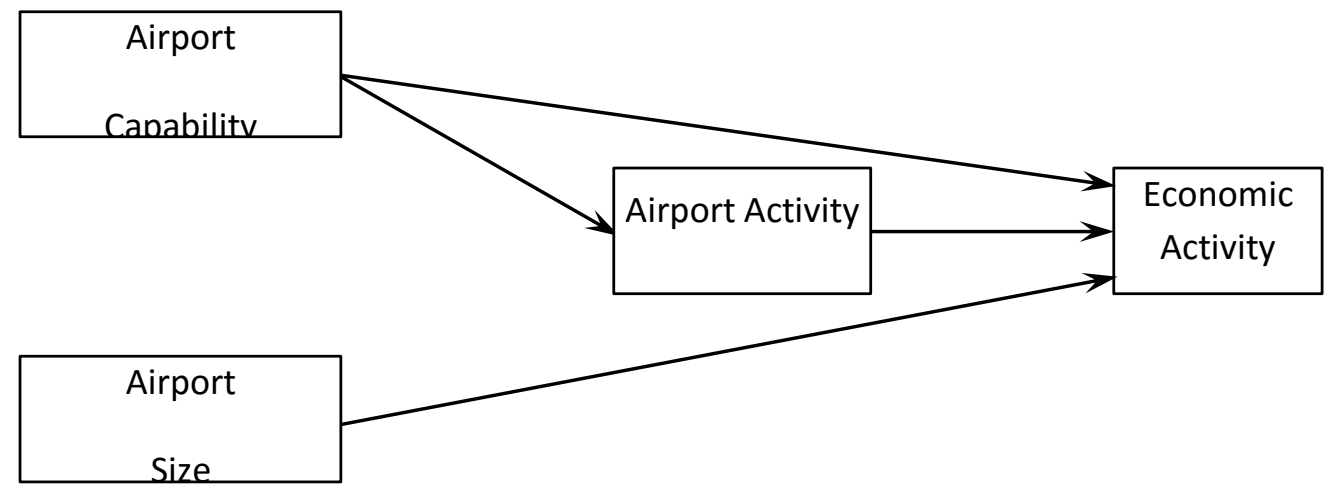

Figure 2. Full Theoretical Model

Next, summary statistics and biserial correlations between the constructs were calculated and are presented in Table 6. Given the established internal validity within each construct, the relationships between them appear quite promising and merit further investigation.

Table 6.

Descriptive Statistics and Pearson Correlation Coefficients ( $N=112)$

\begin{tabular}{|c|c|c|c|c|c|c|c|c|c|}
\hline & Mean & SC & Min & Max & 1 & 2 & 3 & 4 & 5 \\
\hline $1 \mathrm{EA}$ & 0.047 & 0.868 & -1.80 & 2.57 & 1.000 & & & & \\
\hline $2 \mathrm{AA}$ & 8.178 & 1.714 & 3.61 & 12.25 & $0.510^{* * *}$ & 1.000 & & & \\
\hline 3 ACCESS & 0.000 & 1.004 & -1.91 & 2.05 & $0.609^{* * *}$ & $0.481^{* * *}$ & 1.000 & & \\
\hline 4 INFRA & 0.006 & 1.002 & -2.45 & 2.19 & $0.666^{* * *}$ & $0.382^{* * *}$ & $0.457^{* * *}$ & 1.000 & \\
\hline $5 \mathrm{SIZE}$ & 2.732 & 0.880 & 1.00 & 4.00 & $0.673^{* * *}$ & $0.435^{* * *}$ & $0.575^{* * *}$ & $0.562^{* * *}$ & 1.000 \\
\hline
\end{tabular}

Referring to Figure 2, Full Theoretical Model, and the factor loadings and relationships in Table 6, the following hypotheses were investigated:

H1a: Higher levels of airport accessibility results in higher levels of airport activity.

H1b: Higher levels of airport infrastructure results in higher levels of airport activity.

H2a: Higher levels of airport accessibility results in higher levels of EA.

H2b: Higher levels of airport infrastructure results in higher levels of EA.

H2c: Higher levels of airport activity results in higher levels of EA.

H2d: Larger airports is associated with higher levels of EA.

H3a: Airport Activity amplifies the relationship between airport accessibility and EA.

H3b: Airport Activity amplified the relationship between airport infrastructure and EA. 
The conditioned dataset with all variables and constructs as described was used to test the hypotheses. The process for analyzing the data is described in the next section.

\section{Analysis}

Path analysis was performed using IBM SPSS AMOS 21 to analyze the theoretical relationships (direct and indirect effects) between airport accessibility, infrastructure, airport activity, and economic activity. The path coefficients were estimated using the maximum likelihood method and the variance-covariance matrix.

The model demonstrated good fit with the sample data. The chi-squared statistic was not significant $\left(\chi^{2}=\right.$ 2.566, $\mathrm{df}=1, \mathrm{~N}=112, \mathrm{p}=0.109)$ indicating that we cannot reject the null that the covariance matrix in the sample can be modeled as shown in Figure 3. The normed fit index (NFI $=0.989)$, and comparative fit index $(\mathrm{CFI}=0.993)$ confirm good fit with values greater than 0.9. In smaller samples, such as in this study, the CFI has been shown to be less biased (Bentler, 1989). The standardized path coefficients, shown in Figure 3, were all statistically significant at the $\mathrm{p}<0.05$ confidence level or better.

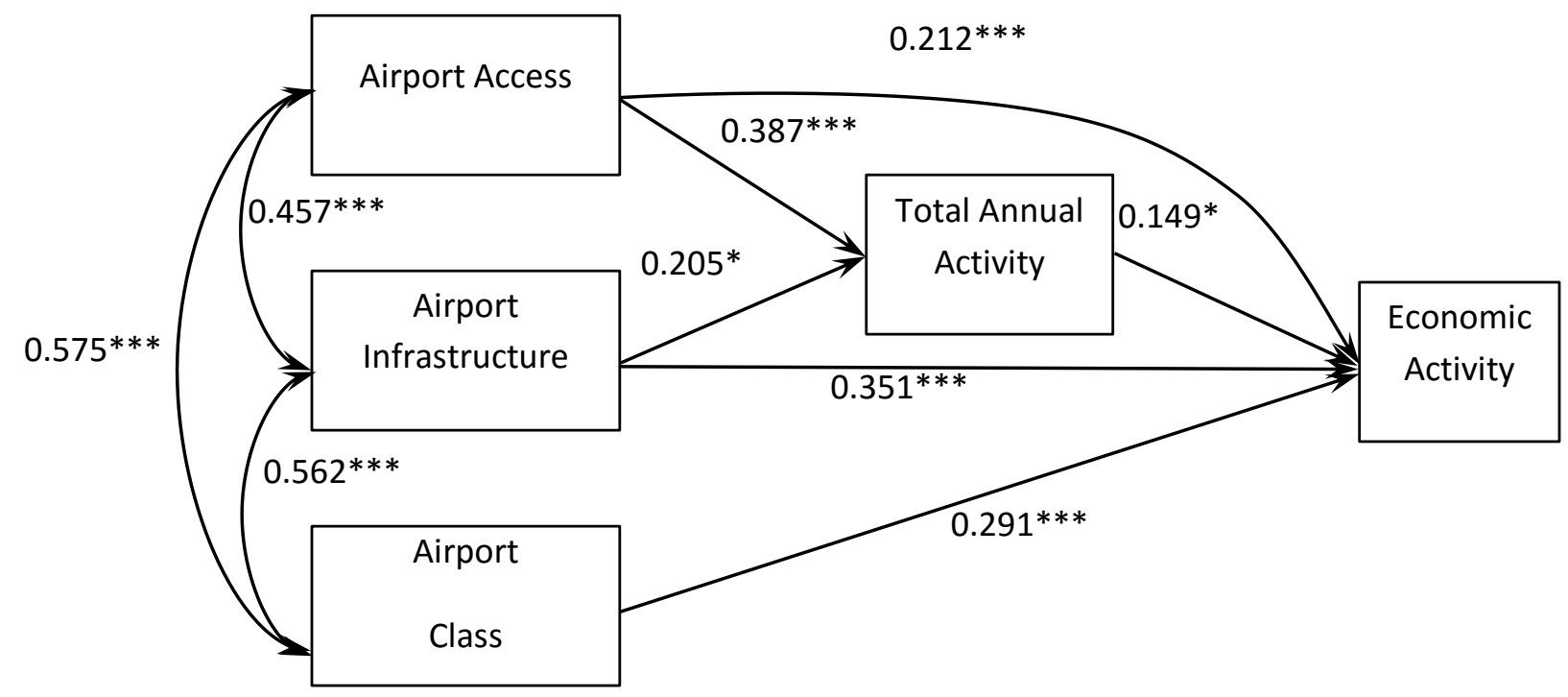

${ }^{1}$ Standardized path weights are reported

$(* * * p<0.001, * * p<0.01, * p<0.05)$

Figure 3. Airport Economic Activity Model

A traditional tabular representation of the association strengths and weight coefficients is presented in Tables 7 and 8 . The model demonstrates both statistical and practical significance well within generally accepted norms for data of this type. Even with a relatively small number of data points, the relationships are strong and non-random. Inference is clouded by the transformations used on some of the variables, and will be discussed in the next section. 
Table 7.

Regression Analysis

\begin{tabular}{lcc}
\hline Variable $^{1}$ & Model 1 $^{2}$ & Model 2 $^{2}$ \\
\hline Constant & DV: Airport Activity (AA) & DV: Economic Activity (EA) \\
ACCESS & $(58.299)^{* * *}$ & $(-4.028)^{* * *}$ \\
& $0.387^{* * *}$ & $0.212^{* *}$ \\
INFRA & $(4.233)^{*}$ & $(2.771)^{* * *}$ \\
& $0.205^{*}$ & $0.351^{* * *}$ \\
AA & $(2.239)^{*}$ & $(4.981)^{*}$ \\
SIZE & & $0.149 *$ \\
& & $(2.210)^{* * *}$ \\
N & & $0.291 * * *$ \\
$\mathrm{R}^{2}$ & 112 & $(3.756)$ \\
Adj R & & 112 \\
F & 0.265 & 0.632 \\
df & 0.251 & 0.619 \\
\hline
\end{tabular}

1: t-statistics are in parentheses

2: *** $\mathrm{p}<0.001,{ }^{* *} \mathrm{p}<0.01,{ }^{*} \mathrm{p}<0.05$

Table 8. Decomposition of the Airport Economic Activity Model

\begin{tabular}{llll}
\hline \multicolumn{3}{l}{ Causal Structural Relationships } \\
& $\begin{array}{l}\text { Direct } \\
\text { Effect }\end{array}$ & $\begin{array}{l}\text { Indirect } \\
\text { Effect }\end{array}$ & Total Effects \\
\hline Annual Airport Activity (AA) & & & \\
ACCESS & 0.387 & & 0.387 \\
INFRA & 0.205 & 0.205 \\
& & & \\
Annual Economic Activity & & \\
(EA) & & & \\
ACCESS & 0.212 & 0.058 & 0.270 \\
INFRA & 0.351 & 0.031 & 0.382 \\
AA & 0.149 & & 0.149 \\
SIZE & 0.291 & & 0.291 \\
\hline
\end{tabular}

${ }^{1}$ Standardized Path Coefficients

\section{Results and Discussion}

We first examined whether higher levels of airport capabilities resulted in higher levels of airport activity, as measured by annual aircraft operations. We found that both airport accessibility (H1a) and airport infrastructure (H1b) resulted in higher levels of airport activity. While this is a basic expectation for any airport, we found that accessibility, in terms of instrument landing capability, has a greater impact on the number of aircraft operations than airport infrastructure. A one standard deviation increase in ACCESS results in a 38.7\% 
increase in the number of operations, while a one standard deviation increase in INFRA only results in a $20.5 \%$ increase in number of operations. This is likely due to the dependence of all operations on the unrestricted (by weather) flow of aircraft into and out of the airport itself; compared to simply having wider, longer runways and more ramp space. Infrastructure cannot be leveraged if it remains idle due to suspended air operations. Activity at the airport not directly dependent on access (e.g. aircraft maintenance, underwriting, research, tourism, or sales activities) do not seem to counterbalance the core dependence on traffic or "fundamentally aviation" type activities. From a managerial standpoint, this suggests that efforts to "broaden" the range of activity aside from flight would not have the same level of results as better approaches with lower decision heights and shorter RVRs. This finding could be used to support resource allocation decisions.

This is somewhat challenged when we looked at "Economic Activity" specifically. We next examined the impact of airport capabilities, airport activity, and airport size on the economic activity at the airport. We found that airport infrastructure $(\mathrm{H} 2 \mathrm{~b})$ and airport size $(\mathrm{H} 2 \mathrm{~d})$ had a larger impact on economic activity than airport accessibility (H2a) and airport activity (H2c), although all relationships were statistically significant. A one standard deviation increase in INFRA resulted in a 0.351 standard deviation increase in the economic activity the most powerful single contributor to economic outcomes. More and longer/wider runways, with higher load bearing capabilities, allows for potentially a wider range of operations from cargo handling to business jets.

The explanation for this seeming contradiction is provided by the (properly described in the model) mediating role of "Activity" with respect to the baseline factors against "Economic Activity." We hypothesized that the number of aircraft operations mediates the relationship between airport capabilities (H3a, b) and economic activity at the airport. We found that airport activity does mediate this relationship, though only partially. If airport activity fully mediated this relationship, then ACCESS and INFRA would not be significant in the full model. However, after decomposing the causal structural relationships, we found the total effect of airport capability is larger than the direct effect for both ACCESS (H3a) and INFRA (H3b). To simplify: while it can generally be said that having both unrestricted access and more capable infrastructure are associated with more operations and therefore more economic activity, a "bigger airport" is not necessarily the key to generating increased economic activity- at least for general aviation airports in the State of Texas. Furthermore, not all activities at the airport are created equal; certain activities (generally those most closely related to flight operations) generate more economic activity than others. The question of "where to invest scarce resources for the highest rate of return" is only partially answered by this investigation.

\section{Summary and Recommendations}

In this study we have demonstrated that strong, significant positive relationships exist between Airport Capabilities (Accessibility and Infrastructure), Airport Size (Class), Airport Activity, and Economic Activity. Investments in infrastructure and access do indeed result in increased economic activity; more so than just "size" (as measured by number of employees). The statistical models used also provided the relative strengths of the relationships; only relative inference is possible due to the variable transformations used. Practical, managerial inferences can also be drawn. First, it is not unreasonable to expect that investment (public or private) in improved airport capability does indeed stimulate increased economic activity directly, and by increasing the number and importance of activities taking place at the airport. In this study, Airport Capability was measured in the form of navaids and associated physical infrastructure to improve the range of operations that can be conducted at the airport. 
Additional research of this type is needed, however, in an effort to more deeply understand these relationships in order to improve the return on investment. It would be helpful, for example, to be able to tell which specific capabilities and activities lead to the greatest increases in economic activity. If there are additional factors that moderate the relationships (increasing or decreasing their strength), analysis of the presence or absence of these factors may indicate better or worse investment choices among airports and capabilities. In addition, these initial results may reflect the dynamics of what works in the state of Texas; a multi-state or national study would be needed to determine if local or regional factors affected the model. Texas is a "block grant" state; where great autonomy is given to local and state level planners when making public investment decisions under the AIP. The nature of the relationships in the model described by this study may differ for non-block grant states. Finally, this study analyzed the contribution of General Aviation operations to economic activity. It is believed the model can be tested against Commercial Aviation (scheduled air service) operations. The efficiency of public investment in airport capabilities may depend on different factors or to different degrees under one market segment vs. the other. It is anticipated that the results of such future research efforts can instruct public policy decisions.

\section{References}

ACI-NA. (2012). The Economic Impact of Commercial Airports in 2010: Airports Council International North America.

Bentler, P. M. (1989). EQS Structural Equations Program Manual: BMDP Statistical Software.

Blanton, W. (2004). On the Airfront. Planning, 70(5), 34-35.

Bombardier. (2013). Bombardier Business Aircraft Market Forecast 2013-2032.

Box, G. E. P., \& Cox, D. R. (1964). An analysis of transformations. Journal of the Royal Statistical Society. Series B (Methodological), 26(2), 211-252.

Doganis, R. (1992). The Airport Business. New York: Routledge.

Doganis, R., Lobbenberg, A., \& Graham, A. (1995). The economic performance of European airports. Cranfield University, Bedford, UK: Department of Air Transport.

FAA. (2011). The Economic Impact of Civil Aviation on the U.S. Economy: Economic Impact of Civil Aviation by State. Washington DC.

FAA. (2012b). Report to Congress: National Plan of Integrated Airport Systems (NPIAS) 2013-2017. Washington DC.

FAA. (2014a). Aeronautical Information Manual: Official Guide to Basic Flight Information and ATC Procedures.

FAA. (2014b). Airport Improvement Program (AIP). Retrieved March 15, 2014, from http://www.faa.gov/airports/aip/

Francis, G., Humphreys, I., \& Fry, J. (2002). The benchmarking of airport performance. Journal of Air Transport Management, 8(4), 239-247. 
Freestone, R., \& Baker, D. (2011). Spatial planning models of airport-driven urban development. Journal of Planning Literature, 26(3), 263-279. DOI: 10.1177/0885412211401341

Gillen, H. W. , \& Lall, A. (1997). Developing measures of airport productivity and performance: an application of data envelopment analysis. Paper presented at the Proceedings of the Aviation Transport Research Group Conference, Vancouver

Humphreys, I., \& Francis, G. (2002). Performance measurement: A review of airports. International Journal of Transport Management, 1(2), 79-85.

ICAO. (2002). Highlights in the Economic Development of Airports and Air navigation Services. Quebec, Canada: International Civil Aeronautics Organization.

Kanafani, A., \& Abbas, M. (1987). Local air service and economic impact of small airports. Journal of Transportation Engineering, 113(1), 42-55. DOI: 10.1061/(ASCE)0733-947X(1987)113:1(42)

Karsner, D. (1997). Aviation and Airports: The Impact on the Economic and Geographic Structure of American Cities, 1940s-1980s. Journal of Urban History, 23(4), 406-436.

Kasarda, J. D. (2000). Aerotropolis: Airport-driven urban development. Urban Land, 59(9 Supp/1), 32-41.

MIG. Inc. (2010). IMPLAN Economic Input-Output Modeling System [software].

Oum, T. H., Yu, C., \& Fu, X. (2002). A comparative analysis of productivity performance of the world's major airports: summary report of the ATRS global airport benchmarking research report-2002. Journal of Air Transport Management, 9(5), 285-297. DOI: 10.1016/s0969-6997(03)00037-1

Pedhazur, E. J., \& Schmelkin, L. P. (1991). Measurement, design, and analysis: An integrated approach. Hillsdale, NJ: Lawrence Erlibaum Associates, Publishers.

Pels, E., Nijkamp, P., \& Rietveld, P. (2001). Relative efficiency of European airports. Transport Policy, 8, 182192.

Peneda, M., Reis, V., \& Macário, M. (2011). Critical factors for development of airport cities. Transportation Research Record: Journal of the Transportation Research Board, 2214(Aviation 2011), 1-9. DOI: 10.3141/2214-01

Robertson, J. A. W. (1995). Airports and economic regeneration. Journal of Air Transport Management, 2(2), 81-88. DOI: http:/ /dx.doi.org/10.1016/0969-6997(95)00033-X

Schlaack, J. (2010). Defining the Airea: Evaluating Urban Output and Forms of Interaction Between Airport and Region. In U. Knippenberger \& A. Wall (Eds.), Airports in Cities and Regions: Research and Practise (pp. 113-126). Karlsruhe: KIT Scientific Publishing.

Sheffi, Y. (2012). Logistics clusters: Delivering value and driving growth. Cambridge Massachusetts: The MIT Press.

TXDOT (2005). Economic impact of general aviation in Texas. Wilbur Smith and Associates

TXDOT. (2011). Economic Impact 2011: General Aviation in Texas. University of North Texas, Department of Economics: Center for Economic Development and Research (CEDR). 
USDOT. (2012). US Department of Transportation Mission Statement. Retrieved March 15, 2014, from http://www.dot.gov/mission/about-us

USDOT. (2014). Moving Ahead for Progress in the 21st Century Act (MAP-21). Retrieved March 15, 2014, from http://www.dot.gov/map21

Weisbrod, G. (1990). Economic Impacts of Improving General Aviation Airports. Transportation research record, 1274, 134-141.

Weisbrod, G. E., Reed, J. S., \& Neuwirth, R. M. (1993). Airport area economic development model. Paper presented at the PTRC International Transport Conference, Manchester, England. 